\title{
Pharmaceutical and Nutritional Properties of Turmeric (Curcuma longa): A Mini Review
}

\author{
Sunidhi Mishra ${ }^{1, *}$, Bharti Goel ${ }^{2}$ \\ ${ }^{1}$ Department of Food Science and Nutrition, College of Community and Applied Sciences, Maharana Pratap University of Agriculture \\ and Technology, Udaipur, India \\ ${ }^{2}$ Department of Food and Nutrition, Home Science College, Punjab University, India
}

Received December 26, 2019; Revised March 4, 2020; Accepted March 19, 2020

Copyright $\bigcirc 2020$ by authors, all rights reserved. Authors agree that this article remains permanently open access under the terms of the Creative Commons Attribution License 4.0 International License

\begin{abstract}
Turmeric (Curcuma longa) is one of the oldest medicinal plants, which has been used from ancient times. Turmeric derived from the Zingiberaceae family and curcumin is the bioactive component in the turmeric. Extensive researches have proven that most of the turmeric activities are due to curcumin. The purpose of this review was to provide a brief summary of the medicinal and nutritional value of curcumin. Turmeric is good source of macro and micronutrients such as protein, energy, vitamin and minerals, and it is known for various medicinal properties with antioxidant activities and is useful in conditions such as inflammation, ulcer and cancer. It has also antifungal, antimicrobial, renal and hepatoprotective activities. Turmeric is being used since past era to modern era; the major application of turmeric is due to antifungal and anti-bacterial property in skin and hair. The recently published papers in international cite as PubMed/ Medline, Science Citation Index and Google Scholar about turmeric were searched. Therefore, turmeric is widely used in treatment of various diseases such as diabetes, osteoarthritis etc. The nutrient content present in the curumin longa is in significant amount, so it can be helpful in combating the nutrients deficiency. Turmeric is also used for Ayurvedic and various cosmetic purposes like blood purification and different types of skin products.
\end{abstract}

Keywords Medicinal Plant, Antioxidant Activity, Curcumin, Nutrients

\section{Introduction}

Turmeric is a plant that has a very lengthy history of medicinal use since almost 4000 years. In Southeast Asia, turmeric is used no longer as an important spice but also used in spiritual ceremonies. It is used due to its wonderful yellow color, turmeric is likewise called "Indian saffron."
Modern-day remedy has begun to apprehend its importance, as indicated by using the over 3000 publications coping with turmeric that got here out inside the ultimate 25 years as shown in figure 1 .

Using turmeric dates back almost 4000 years to the Vedic culture in India, wherein it turned into used as a culinary spice and had some religious importance. It likely reached China by means of 700 ad, East Africa by 800, and West Africa by means of 1200 ad, and Jamaica within the eighteenth century. In 1280, Marco Polo defined this spice, marveling at a vegetable that exhibited features so just like that of saffron line with Sanskrit medical treatises and Ayurvedic and Unani systems, turmeric powder has a protracted records of medicinal use in South Asia. Susruta's Ayurvedic Compendium, courting returned to $250 \mathrm{BC}$, recommends an ointment containing turmeric to alleviate the consequences of poisoned meals (https://www.ncbi.nlm.nih.gov/books/NBK92752/ [24].

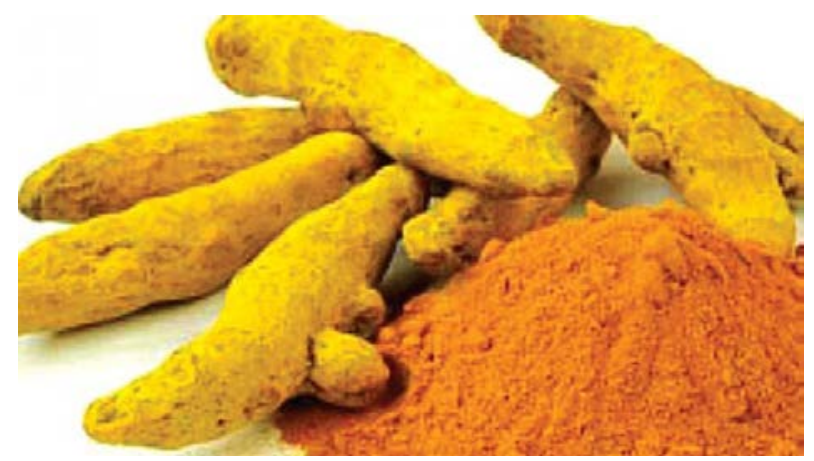

Source: https://www.indiatoday.in/[25]

Figure 1. Turmeric and turmeric powder

\section{Searching Methods}

The recently published papers in international cite such 
as PubMed/ Medline, Science Citation Index and Google Scholar about turmeric was searched.

\section{Phytocomponents of Turmeric}

The medicinal properties of turmeric, the supply of curcumin, were regarded from many years; but, the capability to decide the exact mechanism(s) of action and to decide the bioactive compounds have only these days been investigated as follows: [1]. Curcumin is also referred as diferuloylmethane, is the principle herbal polyphenol observed inside the rhizome of Curcuma longa (turmeric) and in others Curcuma spp [2]. Curcuma longa has been historically used in Asian countries as a medical herb because of its antioxidant, antimutagenic, antimicrobial [4, 5], and anticancer properties [6, 7].

The energetic parts of turmeric are the flavonoid Curcuminoids that aggregates curcumin (diferuloylmethane), monodexmethoxycurcumin and bisdesmethoxycurcum in Curcumin makes up approximately $90 \%$ of the curcuminoid content material in turmeric. Other elements encompass sugars, proteins, and resins. The best-researched energetic constituent is curcumin, which comprises $35.4 \%$ of uncooked turmeric [8].

Turmeric incorporates $69.4 \%$ carbohydrates, $6.3 \%$ protein, $5.1 \%$ fats, $3.5 \%$ minerals, and $13.1 \%$. Moisture. The crude oil (5.8\%) acquired by way of steam distillation possesses squiterpenes (53\%), zingiberene (25\%), a-phellandrene $(1 \%)$, sabinene $(0.6 \%)$, cineol $(1 \%)$, and borneol $(0.5 \%)$. Curcumin $(3-4 \%)$ is responsible for the yellow color, and incorporates curcuminI (94\%), curcumin II (6\%) and curcumin III (3\%). [9]. Turmeric is comprised of a set of three curcuminoids: curcumin (diferuloylmethane), demethoxycurcumin, and bisdemethoxycurcumin, in addition to volatile oils (tumerone, atlantone, and zingiberone), sugars, proteins, and resins. The Curcumin is a lipophilic polyphenol this is nearly insoluble in water however is pretty stable in the acidic $\mathrm{pH}[10]$

Table 1. Biological activity of turmeric and its compound [11]

\begin{tabular}{|c|c|}
\hline Compound Name & Biological activity \\
\hline Curcuma longa & $\begin{array}{c}\text { Antitumor, Anti-protozoan } \\
\text { Anti-inflammatory and } \\
\text { Wound-healing }\end{array}$ \\
\hline Methylcurcumin & Antiprotozoan \\
\hline $\begin{array}{c}\text { Demethoxycurcumin and } \\
\text { Bisdemethoxycurcumin }\end{array}$ & Antioxidant \\
\hline Volatile Oil & $\begin{array}{c}\text { Anti-inflammatory, Antibacterial, } \\
\text { Antifunga }\end{array}$ \\
\hline Curcumin & $\begin{array}{c}\text { Antibacterial, } \\
\text { Antiprotozoan, Antiviral,Antitumor } \\
\text { and Antioxidant }\end{array}$ \\
\hline
\end{tabular}

\section{Nutritive Value of Turmeric}

[Source- Indian Food Composition Table 2017 [23]]

Turmeric is major source of macro and micronutrients. Table 2 shows that it is rich in dietary fibre, food and good source of energy. The vitamins and minerals content in the turmeric are significant. In ancient times turmeric is known as "Golden Spice" because of its various nutritional and medicinal properties, which helps in prevention of many diseases and also enriching the taste and color of the food. Table 3 and 4 reveals the vitamin and minerals content found in the turmeric.

Table 2. Major nutrient in Turmeric per $100 \mathrm{~g}$

\begin{tabular}{|l|l|}
\hline Constituents & Amounts \\
\hline Protein & $7.66 \mathrm{~g}$ \\
\hline Ash & $6.13 \mathrm{~g}$ \\
\hline Total fat & $5.03 \mathrm{~g}$ \\
\hline Total dietary fibre & $21.38 \mathrm{~g}$ \\
\hline Carbohydrate & $49.22 \mathrm{~g}$ \\
\hline Energy & $1174 \mathrm{KJ}$ \\
\hline
\end{tabular}

Table 3. Vitamins content in Turmeric per 100g

\begin{tabular}{|l|l|}
\hline Constituents & Amount \\
\hline Thiamine & $0.06 \mathrm{mg}$ \\
\hline Riboflavin & $0.01 \mathrm{mg}$ \\
\hline Niacin & $1.55 \mathrm{mg}$ \\
\hline Pantothenic acid & $0.13 \mathrm{mg}$ \\
\hline Biotin & $0.76 \mathrm{ug}$ \\
\hline Total folate & $13.86 \mathrm{ug}$ \\
\hline
\end{tabular}

Table 4. Minerals content in Turmeric per $100 \mathrm{~g}$

\begin{tabular}{|l|l|}
\hline Constituents & Amount \\
\hline Calcium & $122 \mathrm{mg}$ \\
\hline Iron & $46.08 \mathrm{mg}$ \\
\hline Copper & $0.44 \mathrm{mg}$ \\
\hline Sodium & $24.41 \mathrm{mg}$ \\
\hline Potassium & $2374 \mathrm{mg}$ \\
\hline Phosphorus & $276 \mathrm{mg}$ \\
\hline Zinc & $2.64 \mathrm{mg}$ \\
\hline
\end{tabular}

\section{Phytopharmacology of Turmeric}

Turmeric is a medicinal plant and it has various therapeutic and pharmacologic activities. There are some major phytopharmacology and therapeutic properties of turmeric.

\section{Antioxidant Activity}

Curcumin lowers the production of reactive oxygen species in vivo. Maintaining the activities of antioxidant 
enzymes like superoxide dismutase, catalase and glutathione peroxidise Recently, it has been observed that curcumin prevents oxidative damage during indomethacin induced gastric lesion not only by blocking inactivation of gastric peroxidase, but also by direct scavenging of $\mathrm{H}_{2} \mathrm{O}_{2}$ and $\mathrm{OH}$. Since Reactive oxygen species have been implicated in the development of various pathological conditions [12], Turmeric has the capability to control these diseases by its potent antioxidant activity.

\section{Gastrointestinal Effects}

Turmeric exerts several protective effects on the human intestine. Turmeric also inhibits ulcer formation caused by stress, alcohol, Indomethacin, reserpine, pyloric ligation, increasing gastric wall mucus in rats subjected to those gastrointestinal insults. It also inhibits intestinal spasm and increases bicarbonate, gastrin, secretin and pancreatic enzyme secretion. An open, phase II clinical trial performed on 25 patients with endoscopically-diagnosed peptic ulcer, with $600 \mathrm{mg}$ powdered turmeric five times daily, result shown that 48 percent of patients were completely healed. No adverse reactions or blood abnormalities were recorded [13].

\section{Osteoarthritis}

Researches reveal that taking turmeric extracts, alone or along with other herbal ingredients, can be helpful in pain management, and also improve the functions in people with knee osteoarthritis. In some research, turmeric worked about also as ibuprofen for reducing osteoarthritis pain. But it does not seem to work as well as diclofenac for improving pain and function in people with osteoarthritis. [14]

\section{Diabetes Mellitus}

Turmeric rhizome powder is very useful with Amla juice and Honey in Madhumeha (diabetes mellitus) [15]. The ingestion of $6 \mathrm{~g}$ turmeric increased postprandial serum insulin levels, but didn't seem to affect plasma glucose levels or Gastrointestinal, in healthy subjects. The results indicate that Curcuma longa may have an effect on insulin secretion [16]. The active principles within the rhizome of Turmeric plant namely curcuminoids lower lipid peroxidation by maintaining the activities of antioxidant enzymes like superoxide dismutase, catalase and peroxidase at higher levels. Antioxidant properties of curcuma longa are due to curcumin and its three derivatives (demethoxycurcumin, bisdemethoxycurcumin and diacetylcurcumin) [17].

\section{Hepatoprotective}

The main constituents of turmeric rhizome ethanolic extract are the flavonoid curcumin and various volatile oils, including tumerone, atlantone, and zingiberene. The hepatoprotective effects of turmeric and curcumin might be because of direct antioxidant and radical scavenging mechanisms, also because the power to indirectly augment glutathione levels, thereby aiding in hepatic detoxification. The volatile oils and curcumin of Curcuma longa exhibit potent anti-inflammatory effects [18].

\section{Efficacy of Turmeric}

Turmeric and curcumin (active component) are approved as GRAS (generally regarded as safe) by FDA (food and drug administration). So, turmeric and its components (curcumin) are mostly used in the butter, mustard, cheese, chips and other products in the United States.

Turmeric helps in cardio protection and functional recovery that helps to decrease in cell death for 1 month at administration of 100-mg/kg turmeric [19]

\section{Uses of Turmeric in Traditional Medicine}

Turmeric is widely used for medicinal purpose such as helps to relieve gas, improves digestion, dispelling worms, regulates menstruation, relieves arthritis, dissolving gallstones and overall energy of the body.

Turmeric and its paste are also used in many ayurvedic applications like blood purification, remedial for skin conditions in Indian country. Turmeric paste is beneficial for hair to remove superfluous hair. In some parts of the India, Pakistan, Bangladesh turmeric is applied on the bride and groom skin before marriage to make skin glow, shine, and helps to keep harmful bacteria away from the body. The multinational companies for the formulation of various sunscreen and face creams mostly use turmeric. Various companies incorporate turmeric in different type of food products like rice and bean dishes that helps in digestion, decrease gas and bloating and turmeric is also mixed with milk or water to treat intestinal disorders as well as colds and sore throats.

In both traditional Chinese and Ayurvedic medicine, turmeric is known as carminative and bitter digestive. It also helps in sprains and swelling as prescribed by Ayurveda from ancient times [20].

Turmeric also acts as dietary supplement as a digestive stimulant that increased the activities of chymotrypsin, amylase and pancreatic lipase. Turmeric also stimulates bile flow, bile acid secretion and mucin content of gastric juice by mixing with other species such as coriander, cumin, black pepper and red chili in rabbits [21, 22]. Turmeric paste is used to heal wounds or to protect against infection. Turmeric is also effective against neuronal, cardiac, and kidney disorders. The effect of turmeric on myocardial apoptosis and cardiac function was examined in an ischemia and reperfusion model of myocardial injury. 


\section{Conclusions}

Curcuma longa (Turmeric), belonging to Zingiberaceae family is one of the most useful herbal medicinal plants in ancient times and modern era both. Turmeric is stock of nutrients; the nutrient content is high in turmeric like protein and dietary fibre. Turmeric is also good source of macro and micro nutrition that helps in regulatory function of the body and acts as health maintains. It has various useful effects of antioxidant activity and also useful in conditions such as inflammation, ulcer and cancer. Therefore, it has the potential to fight against various diseases such as cancer, diabetes, allergies, arthritis, Alzheimer's disease and other chronic and hard curable diseases. Further investigation needs to be carried out on $C$. longa in order to know the concealed areas and their practical clinical applications, which can be used for the welfare of mankind.

\section{REFERENCES}

[1] Gupta S.C., Patchva S., Aggarwal B.B. Therapeutic Roles of Curcumin: Lessons Learned from Clinical Trials. American Association of Pharmaceutical Scientists Journal. 2013; 15: 195-218p.

[2] Aggarwal B.B., Kumar A., Bharti A.C. Anticancer potential of curcumin: Preclinical and clinical studies. Anticancer Research. 2003; 23: 363-398p.

[3] Lestari M.L., Indrayanto G. Curcumin. Profiles Drug Substances Excipients, and Related Methodology. 2014; 39:113-204p.

[4] Mahady G.B., Pendland S.L., Yun G., Lu Z.Z. Turmeric (Curcuma longa) and curcumin inhibit the growth of Helicobacter pylori, a group 1 carcinogen. Anticancer Research. 2002;22 :4179-4181p.

[5] Reddy R.C., Vatsala P.G., Keshamouni V.G., Padmanaban G., Rangarajan P.N. Curcumin for malaria therapy. Biochemical Biophysical Research Communications. 2005;326: 472-474p.

[6] Vera-Ramirez L., Perez-Lopez P., Varela-Lopez A., Ramirez-Tortosa M., Battino M., Quiles J.L. Curcumin and liver disease. Biofactors. 2013; 39: 88-100p.

[7] Wright L.E., Frye J.B., Gorti B., Timmermann B.N., Funk J.L. Bioactivity of turmeric-derived curcuminoids and related metabolites in breast cancer. Current Pharmaceutical Design. 2013;19: 6218-6225p.

[8] Heath DD, Khwaja F, Rock CL. Curcumin content of turmeric and curry powders. FASEB Journal. 2004; 18: $125 \mathrm{p}$.

[9] Ammon HP, Wahl MA. Pharmacology of Curcuma longa. Planta Medica. 1991; 57:1-7p.

[10] Wang YJ, Pan MH, Cheng AL, Lin LI, Ho YS, Hsieh CY et al. Stability of curcumin in buffer solutions and characterization of its degradation products. Journal of Pharmaceutical and Biomedical Analysis. 1997; 15:1867-1876p.

[11] Rahul Kumar Verma, Preeti Kumari, Rohit Kumar Maurya, Vijay Kumar, RB Verma and Rahul Kumar Singh, Medicinal properties of turmeric (Curcuma longa L.): A review, International Journal of Chemical Studies. 2018; 6(4): 1354-1357p.

[12] Bandyopadhyay U, Das D, Banerjee RK. Reactive oxygen species: oxidative damage and pathogenesis. Current Science. 1999; 77:658-666p.

[13] Khajehdehi P. Turmeric: Reemerging of a neglected Asian traditional remedy. Journal of Nephropathol. 2012; 1(1):17-22p.

[14] Dated10.12.2019retrievedfromhttps://www.webmd.com/vita mins/ai/ingredientmono-662/turmeric.

[15] Acharya YT, CharakaSamhitha of Agnivesh with the Ayurveda Dipika commentary (4thedn), Chaukambha Sanskrit Samstha, Varanasi, India. 1994; 447p.

[16] Wickenberg J, Ingemansson S, Hlebowicz J, Effects of Curcuma longa (turmeric) on postprandial plasma glucose and insulin in healthy subjects. Nutrition Journal. 2010; 9: 43p.

[17] Faizal IP, Suresh S, Satheesh Kumar R, Augusti KT, A study on the hypoglycemic and hypolipidemic effects of an ayurvedic drug rajanyamalakadi in diabetic patients. Indian Journal of Clinical Biochemistry. 2009; 24: 82-87p.

[18] Salama SM, Alrashdi AS, Ismail S, AlkiyumiSS, Abdulla MA, et al., Hepatoprotective effect of ethanolic extract of Curcuma longa onthioacetamide induced liver cirrhosis in rats. BMC Complementary and Alternative Medicine. 2013; 13: 56p.

[19] Mohanty I, Arya D. S, Gupta S. K. Effect of Curcuma longa and Ocimum sanctum on myocardial apoptosis in experimentally induced myocardial ischemic-reperfusion injury. BMC Complement Alternative Medicine. 2006; 6:3p.

[20] Araújo M. C, Dias F. L, Takahashi C. S. Potentiation by turmeric and curcumin of gamma- radiation-induced chromosome aberrations in Chinese hamster ovary cells. Teratog Carcinog Mutagen. 1999; 19:9-18p.

[21] Platel K, Rao A, Saraswathi G, Srinivasan K. Digestive stimulant action of three Indian spice mixes in experimental rats. Nahrung. 2002; 46:394-398p.

[22] Mukerji B, Zaidi S. H, Singh G. B. Spice and gastric function: Part I-effect of Curcuma longa in the gastric secretion in rabbits. Lucknow, India: Central Drug Research Institute. Journal of Scientific and Industrial Research.1961;20:25-28p.

[23] T. Longvah R. Ananthan K. Bhaskarachary K. Venkaiah, Indian Food Composition Table. National Institute of Nutrition. 2017; 55-85p.

[24] (https://www.ncbi.nlm.nih.gov/books/NBK92752/ retrieved on December 06, 2019

[25] https://www.indiatoday.in/lifestyle/wellness/story/turmericis-a-miracle-spice-especially-when-used-as-a, n-effective-remedy-for-weight-loss-herbs-health-279399-2 015-12-29 retrieved on December 06, 2019 